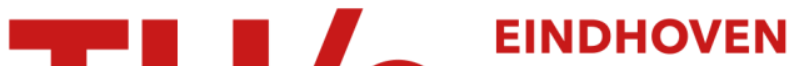 UNIVERSITY OF TECHNOLOGY
}

\section{Professional development for design-based learning in engineering education : a case study}

\section{Citation for published version (APA):}

Gómez Puente, S. M., Eijck, van, M. W., \& Jochems, W. M. G. (2015). Professional development for designbased learning in engineering education : a case study. European Journal of Engineering Education, 40(1), 1431. https://doi.org/10.1080/03043797.2014.903228

DOI:

10.1080/03043797.2014.903228

Document status and date:

Published: 01/01/2015

\section{Document Version:}

Publisher's PDF, also known as Version of Record (includes final page, issue and volume numbers)

\section{Please check the document version of this publication:}

- A submitted manuscript is the version of the article upon submission and before peer-review. There can be important differences between the submitted version and the official published version of record. People interested in the research are advised to contact the author for the final version of the publication, or visit the $\mathrm{DOI}$ to the publisher's website.

- The final author version and the galley proof are versions of the publication after peer review.

- The final published version features the final layout of the paper including the volume, issue and page numbers.

Link to publication

\section{General rights}

Copyright and moral rights for the publications made accessible in the public portal are retained by the authors and/or other copyright owners and it is a condition of accessing publications that users recognise and abide by the legal requirements associated with these rights.

- Users may download and print one copy of any publication from the public portal for the purpose of private study or research.

- You may not further distribute the material or use it for any profit-making activity or commercial gain

- You may freely distribute the URL identifying the publication in the public portal.

If the publication is distributed under the terms of Article 25fa of the Dutch Copyright Act, indicated by the "Taverne" license above, please follow below link for the End User Agreement:

www.tue.nl/taverne

Take down policy

If you believe that this document breaches copyright please contact us at:

openaccess@tue.nl

providing details and we will investigate your claim. 
This article was downloaded by: [Eindhoven Technical University]

On: 16 February 2015, At: 07:18

Publisher: Taylor \& Francis

Informa Ltd Registered in England and Wales Registered Number: 1072954 Registered

office: Mortimer House, 37-41 Mortimer Street, London W1T 3J H, UK

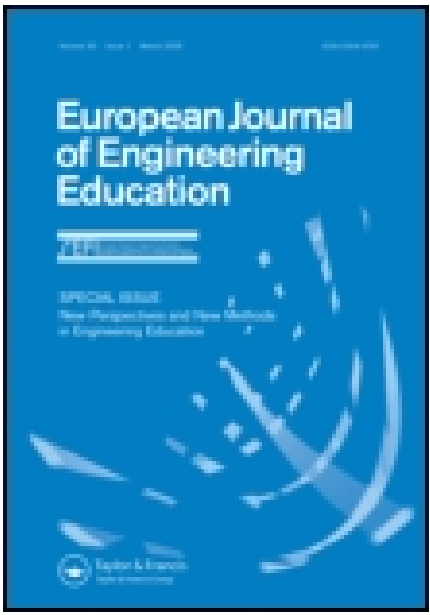

CrossMark

\section{European J ournal of Engineering Education}

Publication details, including instructions for authors and subscription information:

http:// www.tandfonline.com/loi/ ceee20

\section{Professional development for design- based learning in engineering education: a case study}

Sonia M. Gómez Puente ${ }^{a}$, Michiel van Eijck ${ }^{a} \&$ Wim J ochems ${ }^{a}$

${ }^{a}$ Eindhoven School of Education, Eindhoven University of Technology, Den Dolech 2, 5612 AZ, Postbus 513, Eindhoven 5600 $\mathrm{MB}$, The Netherlands

Published online: 01 Apr 2014.

Click for updates

To cite this article: Sonia M. Gómez Puente, Michiel van Eijck \& Wim J ochems (2015) Professional development for design-based learning in engineering education: a case study, European J ournal of Engineering Education, 40:1, 14-31, DOI: 10.1080/03043797.2014.903228

To link to this article: http:// dx.doi.org/ 10.1080/03043797.2014.903228

\section{PLEASE SCROLL DOWN FOR ARTICLE}

Taylor \& Francis makes every effort to ensure the accuracy of all the information (the "Content") contained in the publications on our platform. However, Taylor \& Francis, our agents, and our licensors make no representations or warranties whatsoever as to the accuracy, completeness, or suitability for any purpose of the Content. Any opinions and views expressed in this publication are the opinions and views of the authors, and are not the views of or endorsed by Taylor \& Francis. The accuracy of the Content should not be relied upon and should be independently verified with primary sources of information. Taylor and Francis shall not be liable for any losses, actions, claims, proceedings, demands, costs, expenses, damages, and other liabilities whatsoever or howsoever caused arising directly or indirectly in connection with, in relation to or arising out of the use of the Content.

This article may be used for research, teaching, and private study purposes. Any substantial or systematic reproduction, redistribution, reselling, loan, sub-licensing, systematic supply, or distribution in any form to anyone is expressly forbidden. Terms \& 
Conditions of access and use can be found at http://www.tandfonline.com/page/termsand-conditions 


\title{
Professional development for design-based learning in engineering education: a case study
}

\author{
Sonia M. Gómez Puente*, Michiel van Eijck and Wim Jochems \\ Eindhoven School of Education, Eindhoven University of Technology, Den Dolech 2, 5612 AZ, \\ Postbus 513, Eindhoven 5600 MB, The Netherlands
}

(Received 26 August 2013; accepted 25 February 2014)

\begin{abstract}
Design-based learning (DBL) is an educational approach in which students gather and apply theoretical knowledge to solve design problems. In this study, we examined how critical DBL dimensions (project characteristics, design elements, the teacher's role, assessment, and social context) are applied by teachers in the redesign of DBL projects. We conducted an intervention for the professional development of the DBL teachers in the Mechanical Engineering and the Electrical Engineering departments. We used the Experiential Learning Cycle as an educational model for the professionalisation programme. The findings show that the programme encouraged teachers to apply the DBL theoretical framework. However, there are some limitations with regard to specific project characteristics. Further research into supporting teachers to develop open-ended and multidisciplinary activities in the projects that support learning is recommended.
\end{abstract}

Keywords: design-based learning; experiential learning; situated learning

\section{Introduction}

Design-based learning (DBL) is an educational approach in which students gather and apply theoretical knowledge to solve design problems. DBL is rooted in active learning methods that facilitate students' learning processes. Five dimensions are relevant to the context of DBL. Based on a literature review we defined these dimensions as project characteristics, design elements, role of the teacher, assessment, and social context (Gómez Puente, van Eijck, and Jochems 2011, 2013a).

DBL has been used to help students apply natural science concepts in secondary education. There are successful examples of DBL practices in high school curriculum to teach science (Apedoe et al. 2008; Doppelt et al. 2008; Doppelt 2009). Despite the fact that DBL has been investigated empirically in high school settings, in engineering education, however, research on DBL is scarce and the DBL characteristics in design projects have not been comprehensively investigated. In this study, we explore how teachers apply the DBL characteristics in redesigning their projects. Mechanical Engineering (ME) and Electrical Engineering (EE) teachers take part in a professional development programme, based on the Experiential Learning Cycle (ELC) as an instructional method to introduce the DBL theoretical framework, as well as to present good

*Corresponding author. Email: s.m.gomez.puente@tue.nl 
practices from engineering projects in order to encourage teachers to reflect critically on their own DBL projects.

In the next section, we provide a snapshot of the DBL theoretical framework. Subsequently, we present previous empirical research on DBL. We then describe the guiding educational principles that have given form to the professionalisation intervention with the DBL teachers and supervisors. We present the research method and the participants of this study. Next, we describe how we have used the ELC model as an instructional design approach during the professional development programme. Thereafter, we give examples of the application of DBL characteristics in the redesign of projects. Finally, we present our conclusions and discussion, along with implications for further research.

\section{Background}

\subsection{The theoretical framework of $\mathrm{DBL}$}

DBL is an educational approach that has been mostly used in the context of secondary education to teach science (Apedoe et al. 2008). Grounded in active learning methods, such as Learning by Design (Kolodner 2002) and Design-Based Science (Fortus et al. 2004), DBL has served to help students acquire problem-solving and analytical skills common to science classes while they work on design assignments.

In the context of higher education, however, DBL is rooted in the educational principles of problem-based learning (PBL) (De Graaff and Kolmos 2003) as a way to develop inquiry skills and integrate theoretical knowledge by solving ill-defined problems (Kolodner et al. 2003). Distinctive elements of the approach emphasise the planning process embedded in engineering assignments (Mehalik, Doppelt, and Schunn 2008) while applying knowledge of the specific engineering domain through student involvement in the design activities of artefacts, systems or solutions.

Drawing on the findings of two literature studies (Gómez Puente, van Eijck, and Jochems 2011, 2013a), we framed DBL within five dimensions: project characteristics, design elements, the role of the teacher, assessment, and the social context. With regard to project characteristics, our findings reveal that engineering design assignments are open-ended, authentic, hands-on, and multidisciplinary. Examples of these characteristics are, for instance, assignments in which students work with incomplete information (Mese 2006), devise their own design work plan (McMartin, McKenna, and Youssefi 2000), seek alternatives and consider design solutions (Roberts 2001) in scenarios representing industry problems (Hirsch et al. 2001; Massey, Ramesh, and Khatri 2006; Van Til et al. 2009).

The design elements included in our DBL framework represent design activities conducted in real-life software engineering work places. We have adopted the classification used by Mehalik and Schunn (2006) based on an empirical taxonomy of design elements involving activities from the industry context, such as exploring graphic representation, using interactive/iterative design methodology, or conducting failure analysis (Gómez Puente, van Eijck, and Jochems 2011).

The role of the teacher is to facilitate the learning process and coach and supervise students in DBL assignments. In these assignments, students gather and apply knowledge while working on design projects. In doing so, the teacher formulates questions to facilitate deeper understanding of design tasks (Hirsch et al. 2001; Roberts 2001; Van Til et al. 2009; Etkina et al. 2010), provides formative feedback on technical design progress as a meaningful method in the process of building domain knowledge (Massey, Ramesh, and Khatri 2006; Chang, Yeh Liao, and Chang 2008), encourages students to articulate engineering terminology during regular meetings and presentations (Hirsch et al. 2001; Mckenna et al. 2006; Maase and High 2008), and supports reflection to explicate rationale for technical design, procedures, or processes 
(Massey, Ramesh, and Khatri 2006; Geber et al. 2010), all while playing an authentic role as a client or manager (Denayer et al. 2003; Martínez Monés et al. 2005; Massey, Ramesh, and Khatri 2006).

The literature on assessment uncovers multiple forms and examples of assessment instruments, such as rubrics, mid-term reports or prototypes, online quizzes, individual or group reports, presentations, homework, and lab reports (Roberts 2001; Massey, Ramesh, and Khatri 2006; Shyr 2012; Zhan and Porter 2010).

Examples of the social dimension include collaborative learning tasks, such as providing feedback to one another's plans or experiment results; collaboration on portions of individual assignments (Denayer et al. 2003; Chang, Yeh Liao, and Chang 2008); presentation of prototypes or final products, sometimes with representatives of the industry; and competitions (McKenna et al. 2006).

The characteristics of DBL present in engineering education at university level have not been comprehensively researched, and therefore, we do not know what the benefits are of this approach for gathering and applying knowledge in solving design problems. The need to empirically investigate DBL as an educational concept and what the effects of the DBL characteristics are on the students becomes essential to shed light on DBL as an educational approach suitable for engineering disciplines. We are particularly interested in learning how these DBL characteristics can be introduced in design projects in order to facilitate students' learning processes. In this study, we aim, in particular, to explore how teachers apply DBL characteristics in the redesign of DBL projects. The redesign of the projects to include DBL characteristics will be the first step towards changing teachers' behaviour, as it is expected they will introduce this approach within the projects, according to our framework. This will allow us in a later stage to research the effects of DBL characteristics. We assume that working closely with the teachers will contribute to their professionalisation and assure ecological validity in educational practice.

\subsection{Research context}

DBL was introduced in 1997 at the Eindhoven University of Technology following a worldwide trend to provide students in engineering with knowledge and competencies to develop innovative solutions in response to societal and industry demands (Wijnen 2000). Although DBL is grounded in the educational principles of PBL, it was integrated into engineering programmes in order to encourage students to gather and apply theoretical knowledge in design assignments. We organised a number of visits and study tours with both teachers and students to Aalborg and Roskilde universities in Denmark (Perrenet, Bouhuijs, and Smits 2000) with the purpose of presenting problem-oriented, project-based learning from the PBL model (Kolmos 2002).

DBL was introduced as an educational approach consisting of six features: professionalisation, activation, cooperation, creativity, integration, and multidisciplinary. However, this educational approach has developed into different forms according to the needs of each engineering programme and curriculum purpose. At the ME department, the PBL approach from University of Maastricht was adapted to give form to teamwork assignments in which students gather and apply knowledge in problem-solving and design tasks. Other features adapted from the PBL model were the supervision system with tutors and the '7-jump' group work methodology. DBL at the EE department emerged from the traditional practical instructional form.

As the practice of DBL has evolved over the years and has been adapted to give form to the different engineering study programmes and curriculum purposes, we were interested to know how DBL is performed in practice within the different engineering disciplines. Furthermore, our interest lies in learning how we can improve these DBL practices by comparing the results of our previous study (Gómez Puente, van Eijck, and Jochems 2013b) with the redesign of DBL projects after our intervention in this study. 


\subsection{Previous research on $D B L$}

We conducted a quantitative survey of teachers' and students' perceptions of second-year DBL projects with respect to DBL characteristics in four engineering departments: ME, EE, Built Environment (BE), and Industrial Design (ID). In addition, we carried out a qualitative analysis of DBL projects to identify whether the DBL characteristics included in our theoretical framework actually are present in the projects assigned (Gómez Puente, van Eijck, and Jochems 2013b).

Results from the survey reveal there are differences in perceptions between the departments with respect to the presence of DBL characteristics. ID teachers and students identify the DBL characteristics to a greater extent than those in the other departments. Significant differences are found when we look at project characteristics, the role of the teacher, and design elements among the departments. With respect to assessment and social context, we cannot make rigorous statements since the outcomes regarding these two dimensions appeared less reliable. This might be due to the formulation of questions, to the low number of items included in these two dimensions, and to differences between departments in the implementation of DBL.

When analysing projects, findings indicate that not all DBL dimensions are embedded in the projects throughout all departments. We find differences in some aspects of project characteristics, the role of the teacher and design elements. These differences are encountered mainly in ME and EE when compared to the practices in BE and ID.

Furthermore, we reviewed the second-year DBL projects following a protocol we developed (Gómez Puente, van Eijck, and Jochems 2013b), comprising characteristics of DBL projects from the literature. We followed Yin's (2009) model to design and validate this protocol. Examples of DBL characteristics encountered in the literature included in our protocol are 'Projects are open-ended, e.g. no unique solution is given in the end, looking for alternatives is encouraged'; 'During project implementation, teacher gives regularly individual feedback on content contributions to the project progress (e.g. conceptual and technical design, prototype)'; and 'When student teams are involved in projects, students test hypothesis and explore the reasons for a design to fail'.

The outcomes of the analysis of the project materials indicate there are differences in the DBL projects with respect to project characteristics, the role of the teacher and design elements, and to a lesser extent with regard to the social context and assessment. When looking at project characteristics, we find differences in the areas of open-endedness, authenticity, and multidisciplinary elements. Variation between the departments also exists with respect to the role of the teacher. At ID and BE, coaching and supervision take place on technical design aspects, on process, and on self-development. In ME and EE, however, coaching is limited to technical design aspects and coaching and supervision to the design process. Formative feedback is encountered in the BE, EE, and in ID practices; in ME projects, however, students are assessed at the end based on project reports. With respect to design elements, differences mainly refer to iteration, reflection on process, and communication with users through prototype exposure to external parties, stakeholders, or groups of teachers.

Thereafter, we conducted research on teachers' and supervisors' actions in coaching students (Gómez Puente, van Eijck, and Jochems, 2013a). Results of this research, based on observations and interviews, show that teachers' and supervisors' do not always perform the coaching actions we see in the DBL literature. In addition, interviews with the supervisors reveal that coaching and feedback were intuitive, not formalised, and rarely took place with the use of criteria.

According to the above research findings, we have conducted an intervention for the professional development of DBL teachers with the aim of enabling them to redesign their projects according to the DBL theoretical framework. In doing so, we looked for a vision to frame the teachers' professionalisation path following current trends. In the coming section, we specify the professional development programme we used for the DBL teachers. 


\subsection{The professional development of the teachers}

In contemporary research on the professional development of teachers, interventions considered promising are those situated in the context of engaging teachers in inquiry and reflection about their own concrete classroom situations on educational practices, together with colleagues (Schön 1983; McAlpine et al. 1999; Healy 2000; Hoekstra et al. 2009; Van Veen et al. 2010). Likewise, other examples of interventions are those involving the teachers in the analysis and formative evaluation of their own educational experiments and practices used iteratively to develop education (Cobb et al. 2003; Van den Akker 2003).

Building upon the above-mentioned principles and in line with the educational theories and models from the engineering projects in our literature review (Gómez Puente, van Eijck, and Jochems 2012), we were interested in exposing teachers to best practices in situated design scenarios representing realistic engineering design activities. In these scenarios, learning is situated in real-world, complex tasks that engage students in solving meaningful problems. Displaying these types of examples will inspire teachers to construct authentic and realistic design assignments (Jonassen, Strobel, and Lee 2006).

We selected the ELC by Kolb (1984) as a constructivist learning model to work with teachers during professionalisation sessions. This inquiry model, based on inductive and deductive principles, builds upon experiencing insights and situations, reflecting upon own practices (Schön 1983), generalising and understanding the new DBL insights, and applying new ideas in the redesign of DBL projects. This process resembles analogies of design easily recognised by teachers in engineering disciplines. The iterative character of this model reproduces the engineering design approach of developing products and systems following a process of analysis, reflection and communication on a prototype, and finally, application and testing in a new context. This approach allows teachers to review practices and redesign DBL projects.

We have taken the ELC model and adapted it to our own context for the professionalisation sessions with the teachers. Figure 1 shows how we have adapted it to give structure to our programme.

\subsection{Research questions}

Following a line of investigation from our theoretical framework to the analysis of the implementation of DBL in the engineering study programmes and the professionalisation of DBL teachers, we were interested in exploring the following research questions:

- To what extent have the ME and EE teachers applied the DBL theoretical framework in the redesign of the projects as a result of a professionalisation programme using the ELC as an educational method?

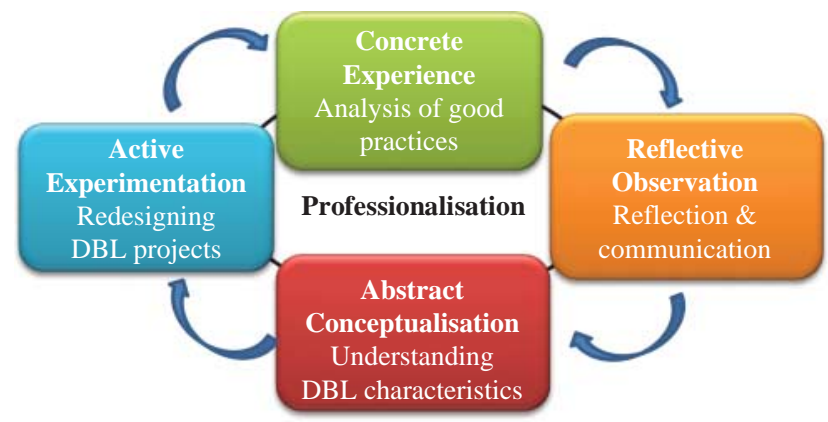

Figure 1. Adapted from the ELC (Kolb 1984). 
- Are there improvements in the redesign of these projects when compared to the projects of our previous study?

\section{Selection of participants and method}

\subsection{Selection of projects and selection of participants}

For the purpose of this study, we selected four projects at two departments, ME and EE, following the results of a previous investigation (Gómez Puente, van Eijck, and Jochems 2013c). At the ME department we chose the two projects compulsory for all ME students at the freshman level. The EE projects included in our study were the only two projects assigned in the second year. In Table 1, we provide an overview of the engineering departments and the name of the projects we have employed for this study.

The participants at the ME department were teachers responsible for the design, supervision, and assessment of the four DBL projects at the freshman level. In addition, technical staff deeply involved in the supervision and to a certain extent in the project design process was also selected. In total $N=6$ teachers took part in the professionalisation meetings. The selection of participants was made by the educational director of the department.

At the EE department, the participants were second-year bachelor teachers who participated in a previous research study (Gómez Puente, van Eijck, and Jochems 2013c). The total number of teachers pertaining to the two DBL projects at the EE department was $N=7$.

Regarding the supervision of students, both the coaches at the ME department and at the EE department responsible for the supervision of the weekly group meetings were also selected. A total of $N=24 \mathrm{ME}$ and $N=15 \mathrm{EE}$ coaches were trained. The main function of the coaches in DBL is to supervise the student groups in weekly meetings. Coaches provide feedback on weekly assignments as well as group performance. In addition, coaches also assess the group and individual work. Coaches at the ME department were master students, senior teachers, and technical staff. In principle, master students act as coaches. However, in case of lack of coaching staff, technical staff and teachers can also act as coaches. At the EE department, coaches were master students. Due to a lack of master students for the second EE project, second-year students were also selected for the supervision of the DBL groups, and consequently, for the training.

\subsection{The method and set-up of professional development for the DBL teachers}

The professionalisation programme consisted of four meetings with, in total, seven hours contact time. The first meeting consisted of an introduction to the research context on DBL. The other three sessions were devoted to the main content areas: the design of projects focusing on project

Table 1. Overview of engineering departments and projects.

\begin{tabular}{ll}
\hline Name of department & \multicolumn{1}{c}{ Name of project } \\
\hline $\begin{array}{l}\text { Mechanical Engineering } \\
\text { First-year projects }\end{array}$ & $\begin{array}{l}\text { Project ME1 - Truss Construction } \\
\text { Project ME2 - The Propeller }\end{array}$ \\
$\begin{array}{l}\text { Electrical Engineering } \\
\text { Second-year projects }\end{array}$ & $\begin{array}{l}\text { Project EE1 - Power Conversion } \\
\text { Project EE2 - Robotic Surgery }\end{array}$ \\
\hline
\end{tabular}


characteristics and design elements, the role of the teacher in supervising and coaching students, and the assessment and social context. In addition, individual feedback was provided on the redesign of the projects.

The professionalisation sessions were structured according to an adaptation of the ELC model as presented in Figure 1. Each session followed the same approach in applying the ELC phases to inspire analysis, reflection through discussion, understanding DBL insights, and finally, application of ideas in the redesign of DBL projects.

During the concrete experience phase, teachers were exposed to examples of best practices from the literature on the five dimensions. Exposure to these experiences served as an eye opener to stimulate inspiration for their own projects. During this phase, examples of open-ended and authentic tasks were presented. For instance, we provided an example from our literature review (Massey, Ramesh, and Khatri 2006): students working on the development of mobile applications by engaging the industry and presenting mobile solutions to an expert panel of industry judges and faculty members. Examples provided concerning the teachers' role refer to the teacher who, during project implementation, provides regular individual feedback on content contributions to the project progress (e.g. conceptual and technical design, prototype). Other examples demonstrate students applying design elements, such as 'test hypothesis and explore the reasons for a design to fail', that stimulate further research on system features to develop a complete prototype.

During the reflective observation phase, teachers reflected on their own practices by comparing their projects to the practices from the DBL literature. Teachers critically analysed their own projects, recognised the limitations and possibilities of DBL within the context of their own classrooms, identified differences between their own projects, and defined opportunities to integrate and reproduce in the context of those projects. With respect to the teachers' role in coaching and supervision, results of research previously conducted on teachers' and supervisor's actions at the ME and EE departments (Gómez Puente, van Eijck, and Jochems 2013a) were presented along with examples from the literature on supervising students. Other illustrations of the teachers' role from our literature (Etkina, Murthy, and Zou 2006; Chang, Yeh Liao, and Chang 2008; Etkina et al. 2010; Geber et al. 2010) displayed teachers' actions by formulating questions, stimulating students to look at the problem from different perspectives, providing formative feedback on students' learning processes, and encouraging self-reflection on their own design practices through iterative prototyping that fostered a critical reflection.

In the abstract conceptualisation phase, teachers gained a better understanding of the DBL characteristics and educational theories. The teachers re-interpreted their ideas and experiences to transform them on engineering design scenarios to enhance students' learning implementation activities as real engineers solving realistic industry problems. In addition, some theory was explained, for instance, on how to design rubrics as an instrument to provide feedback and assessment.

Finally, the active experimentation phase consisted of the redesign and integration of the DBL characteristics into their current projects. Feedback was used to further adjust the projects. The result of the application phase was the project set-up and description for the students. The project documents were used for the analysis of the redesign of the projects. In Figure 2, we present an example of the set-up of an open-ended project, 'Power conversion and distribution system as applied to electric vehicle chargers', at the EE department. In this assignment, students need to design the whole electrical system with few specifications and no architecture to the design.

The professional development programme also included the tutors and project leaders at both departments, as they perform a key role in the supervision and coaching of student groups. Following the DBL model from the literature, the supervisors were trained in the use of rubrics as an instrument for feedback and assessment. In addition, as engineering design is a questiondriven process, the focus on questioning and inquiry was a prominent topic during the sessions 


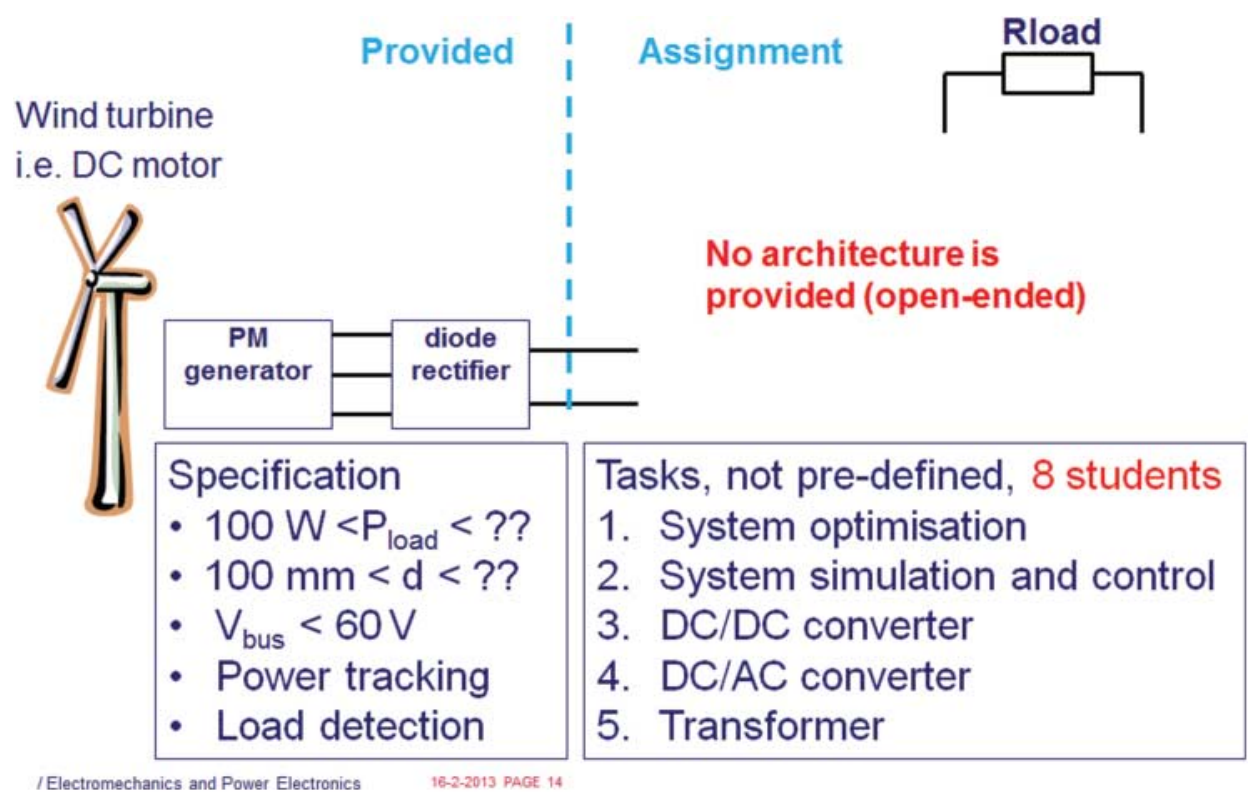

Figure 2. Example of the open-ended assignment of the 'Power conversion' project.

with the tutors and project leaders. Examples of questions and feedback were presented to generate understanding in the actions that supervisors carry out during the coaching of students. These new topics were included in the regular programme for supervisors and consisted of two hours.

\subsection{Analysis of the redesign of the projects' study materials}

We have analysed the project documents the teachers redesigned during the professionalisation meetings. In doing so, we have used a protocol we developed in a previous study (Gómez Puente, van Eijck, and Jochems 2013b). This protocol has been tested before in the analysis of second-year engineering study programmes to examine whether the projects included the DBL characteristics from our theoretical framework. The results of our analysis on second-year projects with the protocol were verified via a check interview with the teachers.

For the purpose of this study, we adapted this protocol slightly with respect to the role of the teacher. The original protocol included items under the teachers' role element that were meant to be used during the interviews. This specific information, however, is not applicable for this study and is therefore not found in the project description and materials developed by the teachers during the instant study. We provide in Table 2 a general overview of some of the DBL characteristics we used in our protocol to analyse the projects' redesign.

\subsection{Verification of findings of the redesign of projects}

To verify the findings of our analysis of the redesign of the projects, we requested an outside researcher, who was not included in this research study, to analyse and review a sample of the projects. We selected the second researcher according to the following criteria: experience in research methodologies, knowledgeable about engineering education and active learning approaches, expertise in project-based education, and familiarity with the DBL characteristics used in this study. We selected one project from each department. The second researcher was instructed 
Table 2. Examples of items used in the protocol for the analysis of project materials

\begin{tabular}{|c|c|c|}
\hline DBL dimensions & Characteristics & Examples \\
\hline \multirow[t]{5}{*}{$\begin{array}{l}\text { Project } \\
\text { characteristics }\end{array}$} & \multirow[t]{2}{*}{ Open-ended } & $\begin{array}{l}\text { No unique solution is encouraged, more than one design } \\
\text { solution/alternative is possible }\end{array}$ \\
\hline & & $\begin{array}{l}\text { Project vaguely formulated: product specifications are not given } \\
\text { or are intentionally unstructured }\end{array}$ \\
\hline & \multirow[t]{2}{*}{ Authentic } & $\begin{array}{l}\text { Realistic scenarios: assignments represent real-life engineering } \\
\text { problems }\end{array}$ \\
\hline & & $\begin{array}{l}\text { Students approach industry to find out information about product } \\
\text { specifications }\end{array}$ \\
\hline & \multirow[t]{2}{*}{ Hands-on } & $\begin{array}{l}\text { Experiential: iterations in analysis prototype design, } \\
\text { implementation, and testing (learning-by-doing) }\end{array}$ \\
\hline Design elements & & $\begin{array}{l}\text { Explore problem representation, use interactive/iterative design } \\
\text { methodology, search the space (explore alternatives), use } \\
\text { functional decomposition, explore graphic representation, } \\
\text { redefine constraints, explore scope of constraints, validate } \\
\text { assumptions and constraints, examine existing designs, explore } \\
\text { user perspective, build normative model, explore engineering } \\
\text { facts, explore issues of measurement, conduct failure analysis, } \\
\text { encourage reflection on process }\end{array}$ \\
\hline Teachers' role & $\begin{array}{l}\text { Coaching on task, process, } \\
\text { and self }\end{array}$ & $\begin{array}{l}\text { Challenge students by asking questions; teacher gives just- } \\
\text { in-time teaching or lecture-by-demand strategy; feedback } \\
\text { upon mid-term deliverables: project plans, project proposal, } \\
\text { prototype }\end{array}$ \\
\hline \multirow[t]{2}{*}{ Assessment } & Formative assessment & $\begin{array}{l}\text { Individual and group tasks; weekly online quizzes; laboratory } \\
\text { work; weekly presentations; reports; prototype; concept design } \\
\text { intermediate checkpoints based on intermediate deliverables: } \\
\text { improvements in reports, prototypes, quality of experiments }\end{array}$ \\
\hline & Summative assessment & $\begin{array}{l}\text { Individual contribution to project group; oral exams; final exam; } \\
\text { presentations; reports }\end{array}$ \\
\hline \multirow[t]{3}{*}{ Social context } & \multirow[t]{3}{*}{ Collaborative learning } & $\begin{array}{l}\text { Team work; communication with real-life stakeholders: } \\
\text { presentations of prototypes to company }\end{array}$ \\
\hline & & $\begin{array}{l}\text { Peer-to-peer communication: peer learning processes within and } \\
\text { across teams when students share laboratory resources and } \\
\text { engage in debates }\end{array}$ \\
\hline & & $\begin{array}{l}\text { Motivation through competitions; variation in design techniques } \\
\text { and approaches: learning principles are the same, but prototype } \\
\text { is different }\end{array}$ \\
\hline
\end{tabular}

oaching on task, process, and self is different

in the DBL characteristics and, subsequently, was asked to analyse the projects following our protocol.

Results of the inter-rater reliability (Gwet 2012) between the two researchers show a moderate to good level of agreement (Cohen's Kappa). The level of agreement for the ME project is .70 (good), and in the EE project .54 (moderate). The major discrepancies among the two researchers are encountered in the interpretation of open-endedness. This may be caused by the fact that the project description and materials to be analysed may not be sufficiently illustrative of the openended character of the assignment. Despite the discrepancy between the researchers regarding this EE project, we still considered this project to include substantial DBL characteristics from our framework, as shown by a comparison of Figure 3(c) and 3(f), indicating a significant improvement after the intervention. The results of the redesign were sufficient for the researchers to determine that the EE department had met the expected standards.

However, being aware of this limitation, a possible remedy in conducting future studies will include adjusting the protocol document used to analyse the projects. This will include more examples from the literature, clarifying precisely the concept of open-endedness to make external researchers more familiar with this aspect. 
(a)

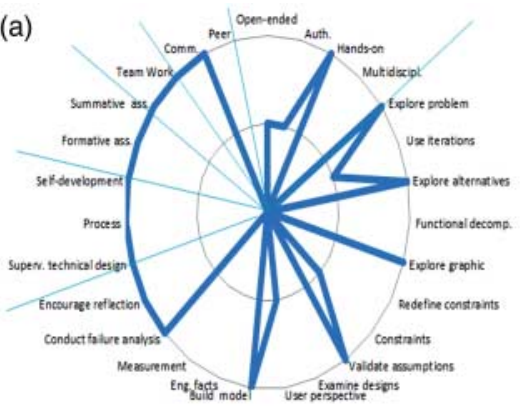

(c)

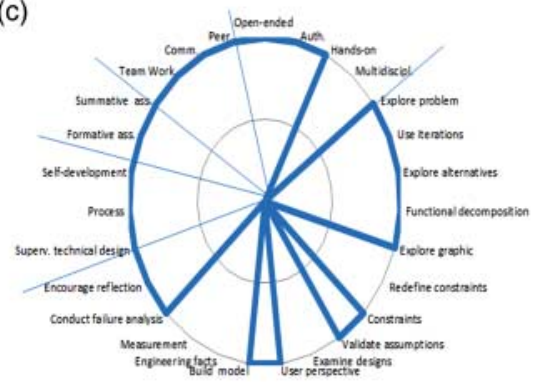

(e)

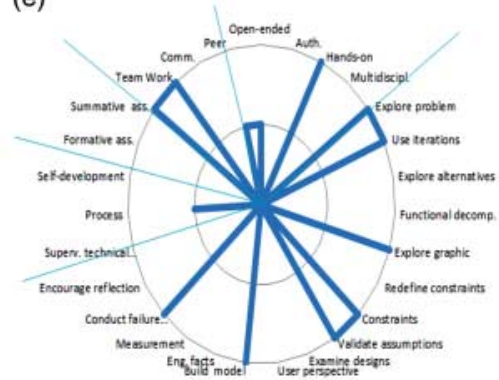

(g)

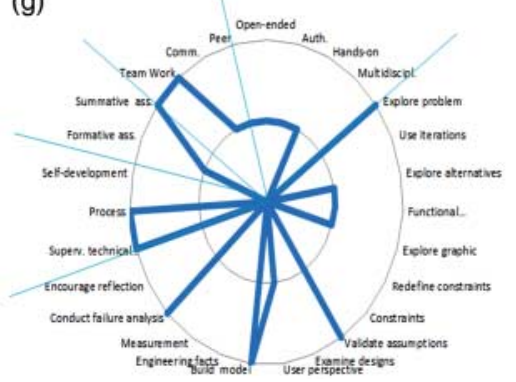

(b)

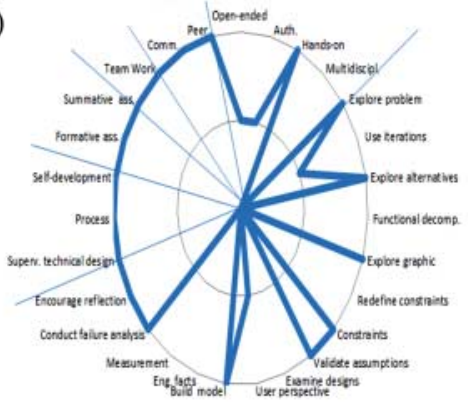

(d)

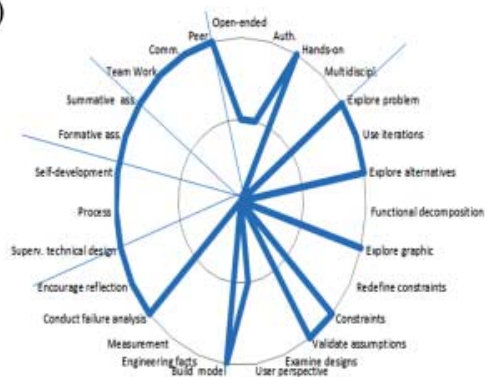

(f)

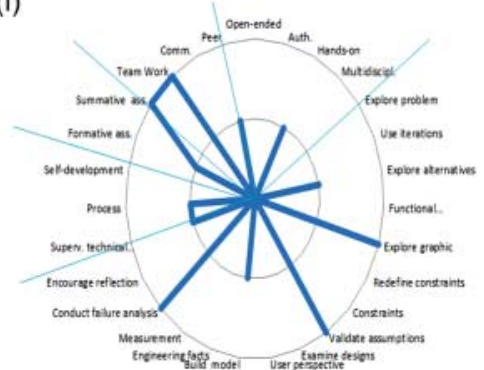

Figure 3. (a)-(g). Description of the DBL characteristics following the clockwise direction: Project characteristics: open-ended projects, hands-on projects, authentic projects, and multidisciplinary. Design elements: explore problem representation, use interactive/iterative design methodology, search the space (explore alternatives), use functional decomposition, explore graphic representation, redefine constraints, explore scope of constraints, validate assumptions and constraints, examine existing designs, explore user perspective, build normative model, explore engineering facts, explore issues of measurement, conduct failure analysis, and encourage reflection on process. Teacher's role: supervision on technical design aspects, supervision on process, and supervision on self-development. Assessment: formative assessment (individual or group tasks) and summative assessment. Social context: team work, communication, and peer-to-peer activities. (a) ME Project 1; (b) ME Project 2; (c) EE Project 1; (d) EE Project 2; (e) ME Project 2 - before intervention; (f) EE Project 1 - before intervention; and (g) EE Project 2 - before intervention. 


\section{Results}

Section 4.1 presents in detail the results of the analysis of one of the four projects, serving as an example of how the DBL characteristics of our theoretical framework have been employed by the teachers in the redesign of this project. Section 4.2 describes in a more outlined fashion the results of the analysis of all four redesigned projects. We also present the projects from our prior study (Gómez Puente, van Eijck, and Jochems 2013b) in order to compare those with the current redesigns.

\subsection{The redesign of the 'Power conversion' EE project}

Table 3 shows that the project characteristic open-ended is represented as an ill-defined task that launches students in the design of a power transfer system for electric cars. Not all specifications for the architecture for all sub-systems (e.g. power tracking, load detection, DC/DC and DC/AC convertors) are provided, and no unique solution or result is indicated, as shown in the lefthand side in Figure 2. Hands-on approach is to design the system, to determine the functionality and interactions of each sub-system, to research the properties and search alternatives by doing simulations, to build and test prototypes, and finally, to improve models in iterations.

Authentic characteristics are represented by a realistic scenario with students playing the role of engineers in an electronics company hired by a wind turbine manufacturer.

We noticed that no multidisciplinary aspects are encountered or linked to the context of societal, environmental, or economic problems. Theory of different courses, however, is integrated, providing a more interdisciplinary character to this project.

With respect to the design elements, the project includes new design activities, such as encourage reflection on process, explore user perspective, use interactive/iterative design methodology, redefine constraints, and explore scope of constraints, among others.

We notice in the redesign of this project that the role of the teacher is displayed by providing supervision of students' technical design tasks, monitoring the progress using rubrics, and also encouraging the students' development.

Regarding formative and summative assessment, the project assignment focuses on process and products (i.e. planning and design system, reports, and demonstrations of sub-systems). Furthermore, with the development of rubrics, students are coached and assessed during the process, providing opportunities for learning and self-development. Assessment with rubrics has been included to bring objectivity and content validity into the assessment process.

Finally, the social context (e.g. competitions, presentations, and peer-to-peer) is represented in this project by a competition and a mid-term presentation with the client and the expert panel, although no representation of industry stakeholders is included.

\subsection{The redesign of the $\mathrm{ME}$ and $\mathrm{EE}$ projects: overview of outcomes}

We describe in this section the results of the analysis of the ME and EE projects. For each of the projects we carried out a detailed analysis as presented in Table 3. The results of the analysis of these projects are outlined in Figure 3(a)-(d). In the figure, we separate the DBL characteristics with extant lines. Lines touching the outer boundaries on the top of the spider web diagram indicate that the DBL characteristics are present in the project. Lines in the middle point out that the DBL characteristics are represent to certain extent. No lines coming from the centre of the spider web diagram indicate that no DBL characteristics are encountered. To gain a better scope of changes implemented through this study, we compare the redesigns with those projects before our intervention (Gómez Puente, van Eijck, and Jochems 2013b), as shown in Figure 3(e)-(g). 
Table 3. Example of the 'Power conversion' project at the EE department

\begin{tabular}{|c|c|c|}
\hline DBL dimensions & $\begin{array}{l}\text { Examples of DBL } \\
\text { characteristics }\end{array}$ & $\begin{array}{l}\text { Examples of DBL characteristics } \\
\text { integrated in the project }\end{array}$ \\
\hline \multirow[t]{5}{*}{$\begin{array}{l}\text { Project } \\
\text { characteristics }\end{array}$} & Open-ended & $\begin{array}{l}\text { Architecture of the system is not given. Students work on given } \\
\text { specifications of the energy transfer system }\end{array}$ \\
\hline & Authenticity & $\begin{array}{l}\text { Students act as engineers in an electronic engineering company. } \\
\text { Engineering company is hired by wind turbine manufacturer } \\
\text { to demonstrate the technical feasibility of a 'green' contactless } \\
\text { energy transfer based on a small wind farm. System might } \\
\text { be sold to companies offering electric vehicle charging on } \\
\text { their parking lots as well as to homeowners. Approximately } \\
700 \text { hours are available for the project team, representing a } \\
\text { commercial value of EUR 50,000-70,000 }\end{array}$ \\
\hline & Hands-on & $\begin{array}{l}\text { Students work in an iterative process in design and operate } \\
\text { a generation, distribution and contactless power transfer } \\
\text { system for electric cars. Students model and construct } \\
\text { electric circuits; design and test a contactless power delivery } \\
\text { system; manufacture printed circuit boards (PCB); make } \\
\text { demonstrations, try-outs, and adjustments }\end{array}$ \\
\hline & & $\begin{array}{l}\text { There is a client (the teacher) and the experts of the company } \\
\text { (content teacher experts) }\end{array}$ \\
\hline & Multidisciplinary & $\begin{array}{l}\text { No representation of multidisciplinary, but project content } \\
\text { embraces four courses }\end{array}$ \\
\hline $\begin{array}{l}\text { Design } \\
\text { elements }\end{array}$ & & $\begin{array}{l}\text { New design elements included in the project after the redesign: } \\
\text { use interactive/iterative design methodology, redefine } \\
\text { constraints, explore scope of constraints, explore user } \\
\text { perspective, explore issues of measurements, conduct failure } \\
\text { analysis, encourage reflection on process }\end{array}$ \\
\hline Teachers' role & $\begin{array}{l}\text { Coaching on: } \\
\text { - Technical design } \\
\text { - Process } \\
\text { - Self-development }\end{array}$ & $\begin{array}{l}\text { Teacher acts as the client and domain teachers are the experts } \\
\text { Supervision on: } \\
\text { - technical design: reports, demonstrations, presentations } \\
\text { - process: progress of planning, regular short presentations } \\
\text { within the group } \\
\text { - self-development: regular feedback with rubrics by project } \\
\text { leaders }\end{array}$ \\
\hline \multirow[t]{2}{*}{ Assessment } & Formative & $\begin{array}{l}\text { Architecture and planning; draft specification; design review } \\
\text { and the pitch to the client ( } 15 \% \text { of final grade); pitch and } \\
\text { advice to client: go/no-go decision based on the pitch to the } \\
\text { client; PCB designs; individual reports; four sets of rubrics } \\
\text { on individual student performance to the responsible lecturer }\end{array}$ \\
\hline & Summative & $\begin{array}{l}\text { - Demonstration ( } 15 \% \text { of final grade) } \\
\text { - Final reports ( } 40 \% \text { of final grade) } \\
\text { - Grade including motivation for each student to the responsible } \\
\text { lecturer at the end of the project ( } 15 \% \text { of final grade) } \\
\text { - Peer review: give each other feedback ( } 15 \% \text { of final grade) }\end{array}$ \\
\hline Social context & $\begin{array}{l}\text { Team work/competitions, } \\
\text { communication/ } \\
\text { presentations/peer-to- } \\
\text { peer }\end{array}$ & $\begin{array}{l}\text { Competitions: after final demonstration, a prize is awarded to the } \\
\text { best team based on demonstration, functionality of designed } \\
\text { system, accuracy of final specification, dimensions, design } \\
\text { of coils and PCB; presentations with (fictitious) industry } \\
\text { representative, i.e. (fictitious) client }\end{array}$ \\
\hline
\end{tabular}

With respect to project characteristics (open-endedness, authenticity, hands-on, and multidisciplinary) encountered in ME projects, the two projects include open-ended tasks to a certain extent, as illustrated in Figure 3(a) and 3(b). In the 'Truss Construction' project, the design specifications are provided; however, students may choose the two-dimensional model to construct based on calculations and explorations on sketches and prototypes. Likewise, in the 'The Propeller' project, some product specifications are given. Students are to investigate the design properties and make decisions around the diameter of the propeller, the set-up of the motor, etc. Hands-on approach is used to carry out experiments, design and build, and test prototypes. 
With respect to authenticity, the redesign of the ME projects resembles realistic scenarios to solve an assignment for a company representing a real-life situation. Other representations of authenticity include mid-term presentations to a panel of experts in the 'Truss Construction' project. In the 'Propeller' project, authenticity is embedded in engineering practical tasks, having a manufacturer advising on a special motor and battery in the propeller. Multidisciplinary, however, is not found in any of the ME projects, nor are the aspects of other contexts.

Concerning the design elements, we observe that these elements are applied as a tool kit to model project activities. The 'Truss Construction' project includes new design elements, such as explore user perspective in the form of an expert panel during a mid-term presentation, with the purpose of encouraging students' reflection based on results, and consequently, interaction. 'The Propeller' project comprises elements such as explore issues of measurement, explore problem representation, and/or build a model, but use iterative design methodology and encourage reflection are new to this setting following our intervention.

With regard to the role of the teacher, in supervising technical design tasks, the process, and the students' development, the projects include more formative feedback on processes and products. Students are supervised based on mid-term presentations or on a measurement plan. Furthermore, teachers have developed rubrics and criteria lists to monitor the technical progress, the group process, and students' individual development. In terms of formative and summative assessment on process and products, there is a focus on both individual and group contribution and performance.

In our analysis, we perceived that the social context in the form of competitions, presentations to stakeholders, peer-to-peer feedback, etc., is represented in the project 'Trust Construction' by, for instance, a mid-term presentation. Although no company representatives are included in this presentation, an expert panel with representatives of a technical university and a fictitious company client was organised. The competition element was previously included in this project. The redesign of 'The Propeller' includes presentations within the group meetings to enhance students' presentation skills. This is a new element in the social context of the project that responds to new educational policies. In this regard, the ME educational department together with the researchers in this study have developed a rubric instrument to provide objectivity and validity in the peer-to-peer review process.

Regarding the EE project characteristics, open-ended tasks are found in both projects, although in the 'Robotic surgery' project, these are encountered to a lesser extent. In this project, students select different alternatives on sub-system levels and the performance specifications are not given. However, some information is provided. Hands-on characteristics are represented by designing systems following a series of experiments, simulations, and test(s) of the prototypes.

From our analysis we noticed that authenticity is represented in the 'Power conversion' project by students working as engineers in an electronic engineering company, which is hired by a wind turbine manufacturer. The teachers act as clients and experts. Regarding the 'Robotic surgery' project, the scenario previously included an authentic scenario to design a robot arm for a company working with medical equipment. The redesign does not include any new authentic elements in this regard.

No multidisciplinary aspects are encountered in the projects, although the projects are linked to courses holding a more interdisciplinary character. Looking at the design elements, both projects include new activities, such as use iterative design methodology, explore user perspective, and encourage reflection on process; these are the new elements encountered in the set-up of project activities following our intervention.

The teachers' role in the projects is to supervise students on technical design, process, and development of students. Technical supervision takes place by the teacher as the client and by the different domain teachers during mid-term presentations in the 'Power conversion' project. In the 'Robotic surgery' project, supervision on technical design was already included based on interim 
deliverables of prototypes. The technical process is now supervised with the use of rubrics as feedback instruments.

Regarding formative and summative assessment on process and products, this element is now integrated and formalised via the use of rubrics. Social context is now represented by competitions, peer-to-peer collaborative activities, and presentations to fictitious stakeholders, as well as giving feedback and assessing peer interventions.

Concerning the ME projects, we can only compare 'The Propeller' project in general terms, as this was a second-year project that is now taught at the freshman level. In Figure 3(e), we observed that changes were applied in all DBL dimensions in comparison to the former version of this project. Regarding ME1, unfortunately, we cannot make comparisons in the redesign of this project because it is a first-year project, and therefore, it was not part of our previous research study on second-year projects.

Reviewing the EE projects before our intervention, we identified in Figure 3(f) and 3(g) that, for instance, concerning open-endedness the projects, and in particular EE1, information provided to students was well-structured in the previous version and included step-by-step instructions to carry out activities. Likewise, we perceived in Figure 3(f) that the former design did not include authenticity dimensions, as the tasks comprised solving a guided problem. In our analysis of the EE teachers' role, we found that supervision focused on technical aspects but also included technical progress and student development.

In our analysis, we have also identified differences among the projects and the departments, which are found mainly in some aspects of project characteristics, i.e. open-endedness. Although all projects show open-ended features in the design assignments, the set-up of the EE projects reveals a broader character of openness than the ME projects in some aspects. This difference may respond to the fact that the ME projects are at the freshman level, where the emphasis of the curriculum lies on teaching students to work in groups and familiarise themselves with the DBL approach, and later to learn about the heuristics of the design process. The EE second-year projects, however, put students in a higher level of complexity of the design process, building upon the design experiences in the projects assigned during the first year.

With regard to authentic character of the teacher's role, in ME projects the teacher does not play a lifelike role as a client, user, or manager of a company. In the EE projects, the teachers play a more realistic role, as they act as clients and experts regarding the first project, the 'Power conversion'. The supervision role focuses now on the technical feedback, such as prototype design and the process based on intermediate deliverables. In addition, in the EE project teachers plan more frequent supervision opportunities on technical design.

\section{Conclusions}

In this study, we examined to what extent ME and EE teachers apply the DBL theoretical framework in the redesign of their projects as a result of a professionalisation programme using the ELC as an educational method. Furthermore, we also explored whether there are improvements in the redesigned projects in comparison with the projects of our previous study.

Based on our analysis, we can conclude that there are improvements in the redesign of the projects in both departments as a result of the professionalisation intervention. As described above, the projects comprise the DBL characteristics to a greater extent than in the previous study. The fact that this method appears to be suitable to carry out changes in current teacher practices in DBL within two engineering departments allows us to think that it can be successfully applied in other engineering departments at this university, having comparable design projects in their curricula. Furthermore, this result serves to encourage faculty to apply this method and to introduce it in the projects in different engineering disciplines at other technical universities. Moreover, 
following the research done in previous studies (Gómez Puente, van Eijck, and Jochems 2011, 2013a) the examples encountered in the literature upon which we have built our framework are embedded in a broad range of engineering disciplines, showing the suitability of similar practices and approaches in different domains. Therefore, it seems likely that the method is effective in (re)designing DBL-like projects, but of course, additional evidence is necessary. The core element, however, is to work together with teachers in the analysis and reflection of daily projects in their own classroom situations and discover the opportunities allowing for contextualisation. Obviously, educational change can be implemented by developing own scenarios following the DBL educational principles and examples.

In addition, we learned from this experience that the approach used in the professionalisation programme is promising as an instructional method to work with teachers in educational change. To evaluate the effects of our intervention we have followed Kirkpatrick's evaluation model. We have mainly focused on the level of reactions of participants and their opinions about the programme's usability and practicality regarding the context in which they develop projects. Further, focusing on Kirkpatrick's level of behaviour, we have carried out observations of and interviews with teachers and supervisors. We have measured some effects of DBL characteristics on students (Gómez Puente, van Eijck, and Jochems 2013a). The results of this study verify that teaching and supervising staff have changed their behaviour as they apply the DBL characteristics from our framework.

\section{Discussion and implications for further research}

From the results of this study we learn that although the DBL characteristics project characteristics and multidisciplinary are integrated in the projects, they still are present to a lesser degree. We understand that these characteristics are aligned to the organisation of the curriculum and project learning outcomes.

The degree of open-endedness is linked to transferring the responsibility in the learning process from the teachers to the students (Shuell 1996; Vermont and Verloop 1999; Atman et al. 2007; Hmelo-Silver, Duncan, and Chinn 2007). From our study, we perceive that some projects taught in the freshman year contain more limitations regarding open-endedness than the projects carried out in upper levels. In addition, teachers' considerations are that students best learn to design following a heuristic path and that openness grows in the curriculum over the years. In this regard, it can be understood that open-ended is limited in some projects. However, as open-ended also implies a shift in teachers' roles to give students a wider level of autonomy in learning to solve design tasks independently, it is essential to support teachers to develop and implement supervision tools. Creating a means to supervise students' self-direction will help to generate a balance between the openness of the projects without jeopardising students' leaning. Strategies to promote open-endedness in the projects are included already in the DBL framework of characteristics. These can be utilised as resources to design scenarios integrating open-endedness in the projects. Furthermore, to create a balance between the degree of freedom given to the students and supervision methods, the emphasis on the teaching paradigm shift should be intensified. On the other hand, forms of shared regulation at cognitive, affective, and regulative learning function level (Vermont and Verloop 1999) have to be included in the supervision during DBL group work. These learning strategies could be embedded in the supervision of students in technical aspects, the process, and the self-development of the student as a means to remediate the complexity that open-endedness brings about in undertaking design problem-solving tasks. Likewise, multidisciplinary is not present in the projects. Interestingly, the projects do not include aspects from different contexts, such as social, economic, or environmental, which would allow a broader investigation of the design perspective. Involving multidisciplinary elements from this viewpoint 
infers the development of a more elaborate project set-up, outcomes, and assessment criteria, without endangering the time allotted for project work and the orientation of the curriculum.

This study presents also some limitations. Although we perceive adjustments in the redesign of DBL projects of our study, we unfortunately cannot strictly compare the original and the redesigned projects at the ME department. The analysis of the ME projects of our preliminary study focused on the second-year bachelor projects; however, the redesigned projects included in our current intervention are part of the freshman year. The change in scope in the bachelor years responds to management decisions at the departmental level.

Moreover, other limitations in this study are encountered in that this study has been carried out in one university and therefore we are unable to generalise the results. However, these results can be seen as an inspiration for other technical universities to critically review their DBL practices.

Finally, one of our premises was that working closely with educational practitioners in a collaborative environment provides a suitable platform for the professionalisation of teachers, which may influence teachers' behaviour (Kirkpatrick 1994; Fullan 2001). However, we are cautious to make rigid statements in this regard, as we cannot assess the impact of our intervention in teachers' daily practice at this stage.

\section{Acknowledgements}

We would like to thank all first-year bachelor teachers at the ME department and the second-year bachelor teachers at the EE department for their participation in this study. We also thank Natascha van Hattum-Janssen for taking part in this study as a second researcher in the inter-rater agreement analysis of the projects.

\section{References}

Apedoe, X. A., B. Reynolds, M. R. Ellefson, and C. D. Schunn. 2008. "Bringing Engineering Design into High School Science Classrooms: The Heating/Cooling Unit.” Journal of Science Education and Technology 17 (4): 454-465.

Atman, C. J., R. S. Adams, M. E. Cardella, J. Turns, S. Mosborg, and J. Saleem. 2007. "Engineering Design Processes: A Comparison of Students and Expert Practitioners." Journal of Engineering Education 96 (4): 359-379.

Chang, G.-W., Z.-M. Yeh Liao, and Ch.-Ch. Chang. 2008. "A Progressive Design Approach to Enhance Project-Based Learning in Applied Electronics Through an Optoelectronic Sensing Project." IEEE Transactions on Education 51 (2): $220-233$.

Cobb, P., J. Confrey, A. diSessa, R. Lehrer, and L. Schauble. 2003. "Design Experiments in Educational Research." Educational Researcher 32 (1): 9-13.

De Graaff, E., and A. Kolmos. 2003. "Characteristics of Problem-Based Learning." International Journal of Engineering Education 19 (5): 657-662.

Denayer, I., K. Thaels, J. Vander Sloten, and R. Gobin. 2003. "Teaching a Structured Approach to the Design Process for Undergraduate Engineering Student by Problem-Based Education." European Journal of Engineering Education 28 (2): 203-214.

Doppelt, Y. 2009. “Assessing Creative Thinking in Design-Based Learning.” International Journal of Technology and Design Education 19 (1): 55-65.

Doppelt, Y., M. M. Mehalik, C. D. Schunn, E. Silk, and D. Krysinski. 2008. "Engagement and Achievements: A Case Study of Design-Based Learning in a Science Context." Journal of Technology Education 19 (2): 22-39.

Etkina, E., A. Karelina, M. Ruibal-Villasenor, D. Rosegrant, R. Jordan, and C. E. Hmelo-Silver. 2010. "Design and Reflection Help Students Develop Scientific Abilities: Learning in Introductory Physics Laboratories." The Journal of the Learning Sciences 19 (1): 54-98. doi:10.1080/10508400903452876.

Etkina, E., S. Murthy, and X. Zou. 2006. "Using Introductory Labs to Engage Students in Experimental Design.” American Journal of Physics 74 (11): 979-986.

Fortus, D., R. C. Dershimer, J. Krajcik, R. W. Marx, and R. Mamlok-Naaman. 2004. "Design-Based Science and Student Learning." Journal of Research in Science Teaching 41 (10): 1081-1110.

Fullan, M. 2001. The New Meaning of Educational Change. 3rd ed. New York: Teachers College Press, Columbia University.

Geber, E., A. Mckenna, P. Hirsch, and C. Yarnoff. 2010. "Learning to Waste and Wasting to Learn? How to Use CradleTo-Cradle Principles to Improve the Teaching of Design.” International Journal of Engineering Education 26 (2): 314-323.

Gómez Puente, S. M., M. van Eijck, and W. Jochems. 2011. "Towards Characterizing Design-Based Learning in Engineering Education: A review of the literature." European Journal of Engineering Education 36 (2): 137-149. 
Gómez Puente, S. M., M. van Eijck, and W. Jochems. 2013a. "A Sampled Literature Review of Design-Based Learning Approaches: A Search for Key Characteristics.” International Journal of Technology and Design Education 23 (3): 717-732.

Gómez Puente, S.M., M. van Eijck, and W. Jochems. 2013b. "Empirical Validation of Characteristics of Design-Based Learning in Higher Education.” International Journal of Engineering Education 29 (2): 491-503.

Gómez Puente, S. M., M. van Eijck, and W. Jochems. 2013c. "Facilitating the Learning Process in Design-Based Learning Practices: An Investigation of Teachers' Actions in Supervising Students." Research in Science \& Technological Education 31 (3): 288-307.

Gwet, K. L. 2012. Handbook of Inter-rater Reliability. The Definitive Guide to Measuring the Extent of Agreement among Raters. Gaithersburg, MD: Advanced Analytics.

Healy, M. 2000. "Developing the Scholarship of Teaching in Higher Education: A Discipline-Based Approach." Higher Education Research and Development 19 (2): 169-189.

Hirsch, P. L., B. L. Shwom, C. Yarnoff, J. C. Andersom, D. M. Kelso, and G. B. Colgate. 2001. "Engineering Design and Communication: The Case for Interdisciplinary Collaboration." International Journal of Engineering Education 17 (4): 342-348.

Hmelo-Silver, C. E., R. G. Duncan, and C. A. Chinn. 2007. "Scaffolding and Achievement in Problem-Based and Inquiry Learning: A response to Kirschner, Sweller, and Clark. 2006.” Educational Psychologist 42 (2): 99-107.

Hoekstra, A., M. Brekelmans, D. Beijaard, and F. Korthagen. 2009. "Experienced Teachers' Informal Learning: Learning Activities and Changes in Behaviour and Cognition." Teaching and Teacher Education 25 (5): 663-673.

Jonassen, D., J. Strobel, and C. B. Lee. 2006. "Everyday Problem Solving in Engineering: Lessons for Engineering Educators." Journal of Engineering Education 95 (2): 139-151.

Kirkpatrick, D. L. 1994. Evaluating Training Programmes. San Francisco, CA: Berrett-Koehler Publishers.

Kolb, D. A. 1984. Experiential Learning. Englewood Cliffs, NJ: Prentice Hall.

Kolmos, A. 2002. "Facilitating Change to a Problem-based Model." The International Journal for Academic Development 7 (1): 63-74.

Kolodner, J. L. 2002. "Learning by Design: Iterations of Design Challenges for Better Learning of Science Skills." Cognitive Studies 9 (3): 338-350.

Kolodner, J. L., P. J. Camp, D. Crismond, B. Fasse, J. Gray, J. Holbrook, S. Puntambekar, and M. Ryan. 2003. "ProblemBased Learning Meets Case-Based Reasoning in the Middle-School Science Classroom: Putting Learning by Design $^{T M}$ into Practice.” Journal of the Learning Sciences 12 (4): 495-547.

Maase, E. L., and K. A. High. 2008. "Activity Problem Solving and Applied Research Methods in a Graduate Course on Numerical Methods.” Chemical Engineering Education 42 (1): 3-32.

Martínez Monés, A., E. Gómez Sánchez, Y. A. Dimitriadis, I. M. Jorrín Abellán, and B. Rubia Avi. 2005. "Multiple Case Studies to Enhance Project-Based Learning in a Computer Architecture Course." IEEE Transactions on Education 48 (3): 482-488.

Massey, A. P., V. Ramesh, and V. Khatri. 2006. "Design, Development and Assessment of Mobile Applications: The Case for Problem-Based Learning.” IEEE Transactions on Education 49 (2): 183-192.

McAlpine, L., C. Weston, J. Beauchamp, C. Wiseman, and C. Beauchamp. 1999. "Building a Metacognitive Model of Reflection." Higher Education 37 (2): 105-131.

McKenna, A., J. E. Colgate, S. H. Carr, and G. B. Olson. 2006. "IDEA: Formalizing the Foundation for an Engineering Design Education.” International Journal of Engineering Education 22 (3): 671-678.

McMartin, F., A. McKenna, and K. Youssefi. 2000. "Scenario Assignments as Assessment Tools for Undergraduate Engineering Education." IEEE Transactions on Education 43 (2): 111-119.

Mehalik, M. M., Y. Doppelt, and C. D. Schunn. 2008. "Middle School Science Through Design-Based Learning Versus Scripted Inquiry: Better Overall Science Concept Learning and Equity Gap Reduction." Journal of Engineering Education 97 (1): 71-85.

Mehalik, M. M., and C. Schunn. 2006. "What Constitutes Good Design? A Review of Empirical Studies of Design Processes." International Journal of Engineering Education 22 (5): 519-532.

Mese, E. 2006. "Project-Oriented Adjustable Speed Motor Drive Course for Undergraduate Curricula." IEEE Transactions on Education 49 (2): 236-246.

Perrenet, J. C., P. A. J. Bouhuijs, and J. G. M. M. Smits. 2000. “The Suitability of Problem-Based Learning for Engineering Education: Theory and Practice." Teaching in Higher Education 5 (3): 345-358.

Roberts, L. 2001. "Developing Experimental Design and Troubleshooting Skills in an Advanced Biochemistry Lab." Biochemistry and Molecular Biology Education 29 (1): 10-15.

Schön, D. A. 1983. The Reflective Practitioner: How Professionals Think in Action. Library of Congress Cataloging in Publication Data. New York: Basic Books.

Shuell, T. J. 1996. "Teaching and Learning in a Classroom Context." In Handbook of Educational Psychology, edited by D. C. Berliner, and R. C. Calfee, 726-764. New York: Macmillan.

Shyr, W.-J. 2012. "Teaching Mechatronics: An Innovative Group Project-Based Approach." Computer Applications in Engineering Education. 20 (1): 93-102.

Van den Akker, J. H. 2003. "Curriculum Perspectives: An Introduction.” In Curriculum Landscape and Trends, edited by J. van den Akker, W. Kuiper, and U. Hameyer, 1-10. Dordrecht: Kluwer Academic Publishers.

Van Til, R. P., M. W. Tracey, S. Sengupta, and G. Fliedner. 2009. “Teaching Lean with an Interdisciplinary Problem-Solving Learning Approach.” International Journal Engineering Education 25 (1): 173-180.

Van Veen, K., R. Zwart, J. Meirink, and N. Verloop. 2010. Professionele ontwikkeling van leraren: een reviewstudie naar effectieve kenmerken van professionaliseringsinterventies van leraren. Leiden: ICLON. 
Vermont, J. D., and N. Verloop. 1999. "Congruence and Friction Between Learning and Teaching." Learning and Instruction 9 (3): 257-280.

Wijnen, W. H. F. W. 2000. Towards Design-Based Learning. Eindhoven: Educational Service Centre, Eindhoven University of Technology.

Yin, R. K. 2009. Case Study Research: Design and Methods. Applied Social Research Methods. 4th ed., Vol. 5. Thousand Oaks, CA: SAGE Publications.

Zhan, W., and J. R. Porter. 2010. "Using Project-Based Learning to Teach Six Sigma Principles.” International Journal of Engineering Education 26 (3): 655-666.

\begin{abstract}
About the authors
Sonia M. Gómez Puente is a Ph.D. candidate at the Eindhoven School of Education and Educational Advisor and Teacher Trainer at TEACH, the Department of Education and Training at the Eindhoven University of Technology. She specialises in the professionalisation of university teachers. Her key areas of expertise include research and innovation in engineering education; curriculum development and instructional design; competencies development; active teaching methods; supervising students in project groups; and design-based learning.
\end{abstract}

Michiel van Eijck is an associate professor at the Eindhoven School of Education at the Eindhoven University of Technology. His research focuses on issues of authenticity and diversity in science and technology education with regard to the sociocultural dynamics of science and technology.

Wim Jochems is Full Professor of Educational Innovation at the Eindhoven School of Education at the Eindhoven University of Technology, the Netherlands. His research focuses on the innovation of science and technology education. He is particularly interested in the role of science teachers in implementing educational innovations. 